\title{
Innovation In Energy: Dissemination Of Energy Culture Via Serious Gaming
}

\author{
Esra Çalışkan, Gülgün Kayakutlu , Vehbi Tufan Koç \\ Industrial Engineering Department, \\ Istanbul Technical University \\ Maçka Istanbul 34367, Turkey \\ Email: \{caliskanesra, kayakutlu, koctu\}@itu.edu.tr
}

\begin{abstract}
In today's world, the term serious game is becoming more and more popular since these games have a purpose of engaging the user and contributing to the achievement of a specific goal other than pure entertainment games. Serious gaming has high potential and power to transfer knowledge and educate people. Serious games are applied to a large spectrum of application areas ranging from military, government to healthcare. Also, researchers found out that serious gaming is a potential tool in order to enable young people to understand the complexity of sustainability and energy conservation topics and stimulate the energy saving attitudes and behaviors and arising energy conservation awareness in a fun way. This study purposes to disseminate energy culture via developing a serious game for university students. Thus, the paper focuses on serious gaming with a broad range of aspects including the need of serious gaming in various sectors and its benefit for behavior change and its effects on energy culture. While developing the game, the conceptual framework which is called as 'Design Pattern Library' is considered. Description and the flow of the game are determined and the game is played between students. Results obtained by this study will enlighten both researchers and game design experts in terms of disseminating energy culture via serious gaming.
\end{abstract}

Index Terms-Serious Gaming, Energy Culture, Behavioral Change

\section{INTRODUCTION}

$\mathrm{I}^{\mathrm{T}} \mathrm{s}$ $\mathrm{T}$ IS known that the idea of playing a game has emerged since the ancient past and it is still on going as an integral part of today's world. The Dice game which is one of the oldest games discovered by humans is known to be set 3000 years ago in South Iran (as cited in Laamarti et al., 2014). Games are played according to a set of established rules, played out within a specific time frame and a place with a player or a group of players. Indeed, games have always been powerful to affect people's lives in many aspects and still games have huge power on people wherever in the world. It is known that games have power to bring people all together from 7 to 70 and socialize. It is claimed that games are even powerful in revealing and building people's characters (Michael et al., 2006) Most importantly, games have power to teach, to educate and to train. Since most games are claimed to have a primary purpose of entertainment, enjoyment and fun way to pass the time or interact with other players, serious games are distinguished with their serious purposes. IDATE pointed out three main principles of serious games: delivering a message, providing training and enabling the exchange of information (2010). These principles briefly show that serious games have a goal to transmit a message with a serious purpose, to improve the users' cognitive and/or motor skills via trainings and to provide an environment for flow of data between users. Besides, Knol and Vries supported that serious gaming is a potential tool in order to enable young people to understand the complexity of sustainability and energy conservation topics and stimulate the energy saving attitudes and behaviors and arising energy conservation awareness in a fun way (2011). Most importantly, these serious games are explicitly designed to encourage behavioral change. As this study aims to disseminate energy culture via serious gaming, the next part consists of literature review on serious gaming. Also, sample games that aim to change energy related behavior patterns are analyzed. The third part explains how the methodology works for developing a serious game. The game board and the flow of the game 'Enopoly' is given in the fourth part. The fifth part discusses the results of the game and gives suggestions for further studies. This study aims to contribute both researchers and game developers.

\section{Literature Review}

\section{A. Serious Gaming in Various Sectors}

There is a growing evidence that some people responds better to "playful" kind of formats of information feedback and this is why the serious gaming trend raises by using digital games for learning, simulation and demonstration (Wood et al., 2014). Inevitably, the serious game sector is showing significant growth in the medium term. According to IDATE's Serious Gaming Market and Data Report (2010), it is stated that serious gaming is an attractive sector and the players in the sector are grouped into 4 categories as seen on the figure below: Traditional software sector players, groups of investors, intermediate players and the targeted sectors.

The report emphasized on targeted sectors category are mainly consisted of healthcare, teaching and training, information communication promotion, defense and civil security. Indeed, there is a wider segmentation since serious gaming applications can be used in any sectors. To begin with healthcare sector, it is remarked that sector specific aspects are broad and serious games is widely used from marketing of medication brands to provide medical trainings. While some of these applications are used for medical purposes such as helping with diagnosis, preventing illnesses, 


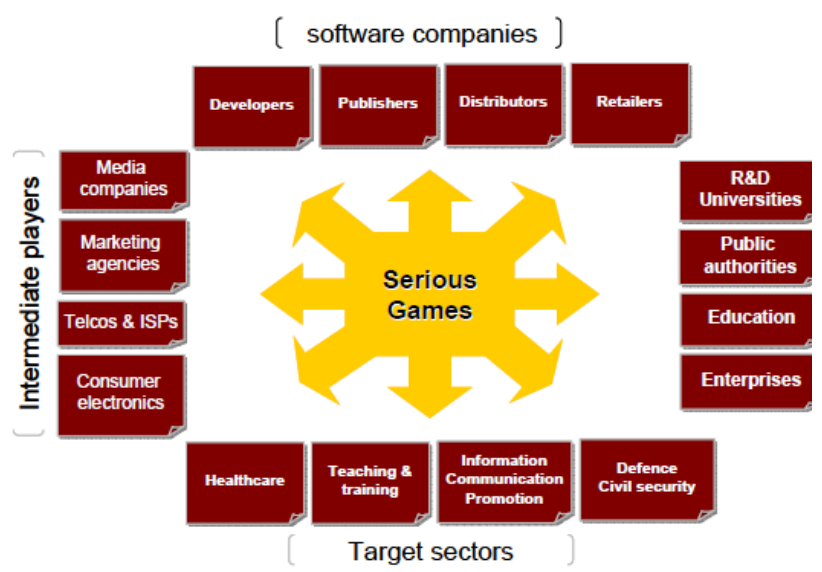

Fig 1. Categories of players involved in Serious Gaming

others offer training, fitness, physiotherapy and also advertising. To discuss the role of serious games in teaching and training sector, these games carried a large spectrum of aims such as teaching social science and physical science, management skills, foreign languages, team building skills etc. Thus, the games are not only presented to general public but also enterprises such as training specialist, manufacturers, military etc. Thirdly, public information and business communication sector is taken into consideration and it remarked that these games are used as an instrument to inform and communicate. When sector-specific serious games are analyzed, the purposes of past applications were diversified such as learning about renewable energy sources, promoting real estates, increasing awareness of flood protection and prevention policies etc. Finally, serious games that are devoted to defense and civil security sector are analyzed. It is found out that mainly, three features of serious games are used in military games: serving as recruitment tool, showcasing the armed forces and serving as training tool for military staff.

\section{B. Sample Games in Energy and Sustainability Field}

Bertoldi et al., asserted that intelligent education of young people which focuses on increasing awareness of the role of energy in societal level and household level and influences their energy related attitudes play an important role in terms of stimulating household energy conservation (as cited in Knol and Vries, 2000). Therefore, there has been many projects devoted energy efficiency, sustainability and renewable energy across the Europe and the serious gaming is considered as an innovative educational concept to reach young people. Compared to traditional educational tools, Bennet et al. asserted that serious gaming has higher potential because today's young people prefer visual information to textual, like to play games, are adapted and oriented to multiple media channels and highly active on social network sites (as cited in Knol and Vries, 2008). According to study of Grossberg et al., 53 games that all have the purpose of influencing behavior around energy efficiency and sustainability have been analyzed and it is found out that these serious games covered a wide range of solutions such as recycling, alternative energy, energy saving, utility efficiency etc. It is found out that these games are providing such common features like clear goals and rules, a compelling study, quick feedback and achievable short-term challenging tasks (as cited in Grossberg et al., 2015). In the study, 'Cool Choices' which is a is a nonprofit sustainability-focused serious game that is used in workplaces and schools and 'EnerCities' game which aims to reach out young people, especially secondary school students to alert and increase their awareness around energy saving and renewable energy are analyzed.

\section{Serious Games for Changing Behavior}

All in all, there are such actions required to take by individuals for energy efficiency and sustainability aspects and these actions are highly related to characteristics of individuals such as age, gender, preferences and attitudes. Therefore, serious games are recommended to change these behavioral patterns of people. It's stated that these games are used to support players in decision making, learning and aim to change behaviors whether the game is played by a single user or multiple users (Wood et al., 2014). To influence the occurrence or frequency of certain set of behaviors, empirical techniques are designed under applied behavior analysis (ABA) which is also called behavior modification (Due et al., 2014). According to researchers, behavior modification has been proven to be effective in different set of fields ranging from health, education to energy. However, these behavior modification methods are widely criticized in terms of resulting in unwanted side effects such as growing emotional disorders due to the punishments, arising hatred because of feeling of being manipulated through positive reinforcement and so on. Furthermore, these procedures of implementing behavior modification have been criticized by some researchers because a specific level of training is required and these trainings are time consuming and the procedures are not practical in terms of aligning with real life. In contrast to behavior modification which is made through imposing or removing a certain stimulus to lead behavioral change, serious games are claimed to achieve same results by creating an engaging experience using the elements of game Moreover, serious games relate such habit changes to positive emotional feedback and encourage positive behavior change in a pleasant and playful way (Schuller et al., 2013)

\section{Methodolgy}

Serious games can be of any genre, use any game technologies and be developed for any platforms (Kankaanranta et al., 2009). Serious games have common points with other games in term of owning its rules, accepting input from players, simulating behaviors and providing feedback within the context of the rules and behaviors (Michael et al., 2006). Therefore, design and development issues of serious games and entertainment games have similarities. Nevertheless, the primary design criteria in serious games highly differs since it is not "fun" but a serious purpose such as training, teaching etc. Thus, these games are more concerned with whether 


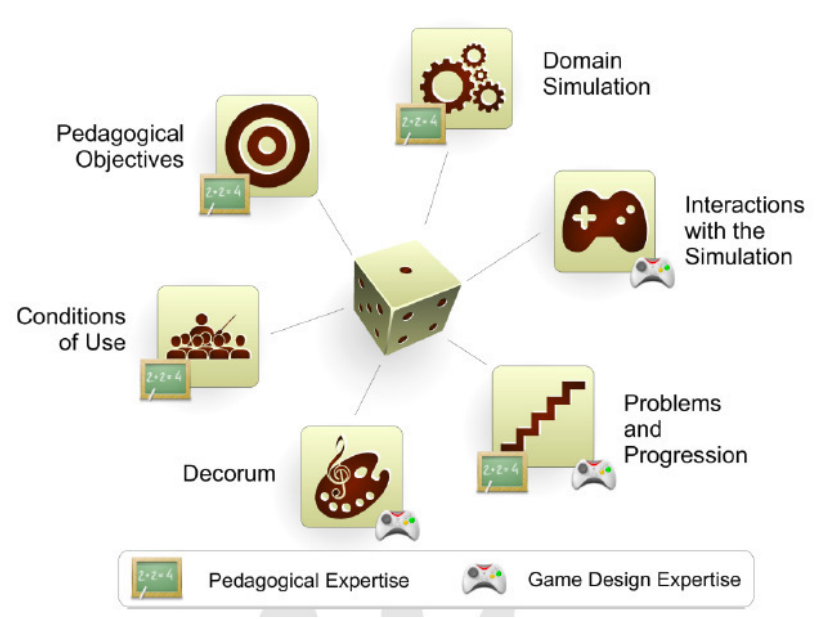

Fig 2. Six Facets of Conceptual Framework

or what the game is teaching and how the players can actually apply these learnt objects in the real life. It is discussed that serious games may be more entertaining but less capable in terms of knowledge acquisition if these were only designed by game developers. On the other hand, teacher or trainers might design such games that are powerful through educational purposes but these games would be lacking in motivating and engaging players (Marne et al., 2012). Thus, it is claimed that the conceptual framework which is called as 'Design Pattern Library' is created to facilitate the cooperation between various stakeholders in design stages of serious games. The stakeholders are grouped into two categories: the pedagogical experts and game experts. While pedagogical experts include educators, knowledge engineers, trainers and domain specialists; game experts consist of game developers, level designers, game producers, graphic and sound designers and so on (Marne et al., 2012). Therefore, six facets of the conceptual framework are used in the study and each facet is described by its title, a serious game design problem and a general solution and its experts. According to Marne et al.'s study, the six facets of the conceptual framework are given as: Pedagogical objectives, domain simulation, interactions with the simulation, problems and progression, decorum and conditions of use (2012). Indeed, the model helps to assign right experts to each of the six design areas of the serious games.

Briefly, pedagogical objectives aim to define the pedagogical content of the serious game and its general solution is to specify the knowledge model of the domain and educational purposes. The second facet, domain simulation, handles the problem of how to respond consistently the correct and incorrect actions taken by game players within a specific certain context. Thirdly, interactions with the simulation defines how to the engage the players when they are allowed to interact with the simulator. The forth facet, which is problems and progression, deals with which problems to give the players to solve and in which order these problems should be arranged. Decorum defines the types of multimedia or fun components of the game, that are not related to the do-

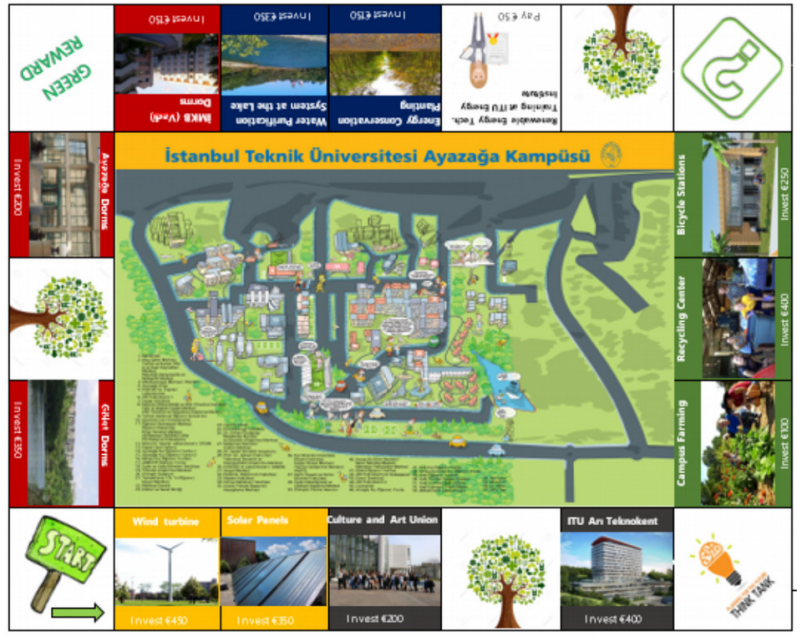

Fig 3. The Game Board

main simulation, to foster the player motivation. Finally, condition of use aims to define where, when, how and with whom the game is played.

\section{The Game}

\section{A. Game Description}

The 'Enopoly' game aims to increase energy saving knowledge of students, to inspire them in terms of initiating energy-related projects in the campus and to increase their desire to continue a career path in energy sector. The game is developed as a board game and it takes place in the main campus of Istanbul Technical University as part of its scenario. As part of the scenario, players are granted with $€ 1250$ by the school rectorate and they aim to invest energy saving projects most wisely. The player who has the highest value of invested projects at the end of the game is selected as winner. The energy saving initiatives and projects at the campus are: Water purification system at the lake, energy conservation planting, bicycle stations, recycling center, campus farming, solar panels and wind turbines. Also, there are traditional buildings to invest such as dorm buildings, ITU Teknokent and Culture and Arts Union building.

Throughout the game, students are picking game cards when they land to specific areas and they lose or earn money based on scenarios related to their being investor of these projects. These areas are specified as below:

Green Reward: Player landing on Green Reward space collects $€ 50$ if she/he has investments in blue, green or yellow areas.

Think Tank: Players landing on Think Tank space lose a turn. During the turn, she/he must generate an energy-saving idea for the campus and share it with other places. Project ideas are pinned to the campus map which is on the game board.

Energy Fact: Players landing on the Energy Fact space must pick up a 'Energy Fact Card' and read it out. 


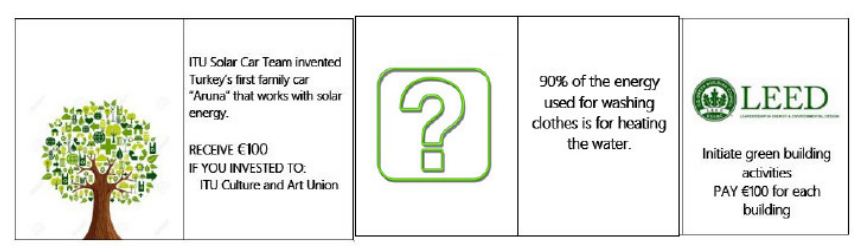

Fig 4. Sample Game Cards (Energy Fact, Environment, Investor and LEED cards in order)

Environment: Players landing on Environment space must pick up an 'Environment Card' and read it out. The player then either collects money from the bank or pays a fine.

Also, players landing on certain areas must pay a charge to the investor that is specified on investor card. Moreover, players earn more if they invest to same colored projects or if they have LEED certification investment for traditional buildings.

\section{B. Game Flow}

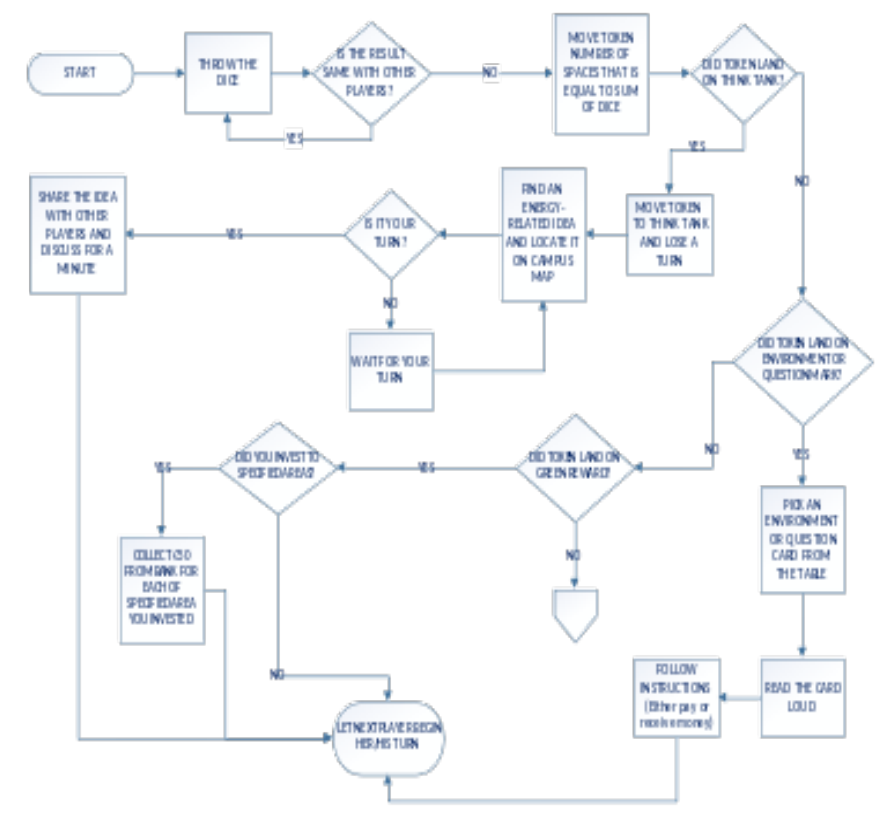

Fig 5. First Part of Game Flow

\section{Case Study}

The game was first played with 10 different students in a classroom and the player groups were composed of 3 to 4 students. Before playing the game, a survey was handled to the students. Therefore, students responded to survey questions without knowing the concept of the game. The reason why students were not introduced to the game was to minimize any bias effects. With these survey questions, it's aimed to measure students' current knowledge, concerns, motivations about energy-related topics, projects and jobs. As certain knowledge, concerns and intrinsic motivations lead behavioral patterns of individuals, the survey results will be used to measure players' current situation. After the collecting pre-game survey answers, group of students were

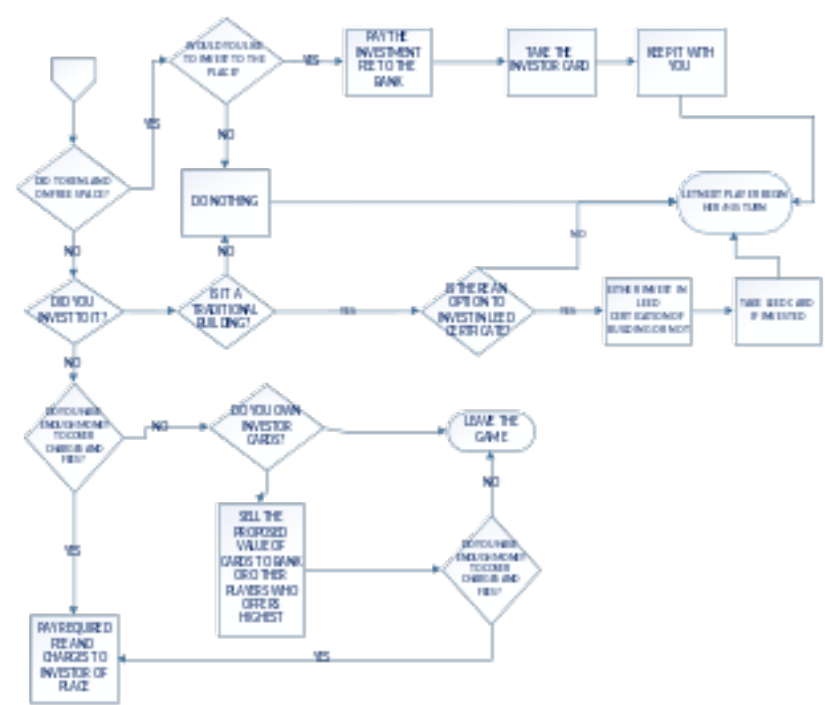

Fig 6. Second Part of Game Flow

introduced to the Enopoly game. At the end of the game, after-game survey questions were handled to players. With these survey questions, it's aimed to measure game's effect on players about their knowledge, concerns, motivations about energy-related topics. Therefore, a comparison between survey results before and after playing the game will be used as an indicator to analyze effect of the game on players

TABLE 1

Comparison of Survey Results

\begin{tabular}{|c|c|c|c|c|}
\hline & \multicolumn{2}{|c|}{$\begin{array}{l}\text { Pre-Game } \\
\text { Results }\end{array}$} & \multicolumn{2}{|c|}{$\begin{array}{l}\text { After-Game } \\
\text { Results }\end{array}$} \\
\hline & Mean & $\begin{array}{l}\text { Std. } \\
\text { Dev. }\end{array}$ & Mean & $\begin{array}{l}\text { Std. } \\
\text { Dev. }\end{array}$ \\
\hline $\begin{array}{l}\text { Interest in learning } \\
\text { about energy saving } \\
\text { and sustainability }\end{array}$ & 4.3 & 1.05 & 4.4 & 0.51 \\
\hline $\begin{array}{l}\text { Awareness about } \\
\text { lowering energy } \\
\text { usage as an } \\
\text { individual }\end{array}$ & 4 & 0.66 & 4.5 & 0.52 \\
\hline $\begin{array}{l}\text { Awareness about } \\
\text { responsibility to } \\
\text { initiate energy } \\
\text { saving projects at } \\
\text { campus }\end{array}$ & 3.6 & 0.96 & 4.4 & 0.69 \\
\hline $\begin{array}{l}\text { Concerns about } \\
\text { environment }\end{array}$ & 4.7 & 0.48 & 4.4 & 0.51 \\
\hline $\begin{array}{l}\text { Consideration of a } \\
\text { career path in energy } \\
\text { sector }\end{array}$ & 2.8 & 1.03 & 3.4 & 0.96 \\
\hline $\begin{array}{l}\text { Desire to get a job in } \\
\text { energy sector }\end{array}$ & 3.2 & 0.63 & 3.6 & 0.84 \\
\hline $\begin{array}{l}\text { Desire to initiate } \\
\text { energy saving } \\
\text { projects }\end{array}$ & 3.6 & 0.84 & 4.1 & 0.73 \\
\hline
\end{tabular}




\section{Results and Discussion}

By taking pre-game and after-game survey results into consideration, a comparison is made to measure the effect of Enopoly game on players. According to the results, it's seen that players' interest in learning about energy saving and sustainability increased slightly and awareness about lowering energy usage as individual increased considerably from 4 to 4.5 . As the game aims to stimulate the awareness and attitude of university students relating to energy saving and sustainability, the results were positively aligned with it. Also, players' awareness about their responsibility to initiate energy saving projects at campus has risen dramatically from 3.6 to 4.4. Throughout the game play, it was observed that players highly enjoyed Think-Tank space as they had opportunity to voice campus energy-saving ideas with other players and have such discussions.

Players indicated that they are already concerned about environment at the before the game play. Therefore, there has not been significant change related to concerns. Additionally, players proved a higher motivation and desire to follow a career path in energy sector after playing the game. Also, the game stimulated players' desires to initiate energy saving projects; there has been a significant increase from 3.6 to 4.1 at the end of the game. It is found that in contrast to behavior modification which is made through imposing or removing a certain stimulus to lead behavioral change, serious games are powerful to achieve same results by creating an engaging experience using the elements of game. Also, it is claimed that serious games relate such habitual changes to positive emotional feedback and encourage positive behavior change in a pleasant and playful way (Schuller et al., 2013) According to the players' feedbacks and observations, Enopoly game made such engaging experience to the players with energy saving and sustainability topics in a playful way. Also, data analyses and student reflections shown that Enopoly has such a power to effect players' knowledge, motivation and intrinsic desires on energy- related topics, projects and jobs.

\section{REFERENCES}

[1] Bensch, I. (2012). Miron Construction's iChoose Game. Energy Center of Wisconsin.

[2] Consumption of energy. (n.d.). Retrieved January 15, 2016, from http://ec.europa.eu/eurostat/statistics-explained/. Eurostat.
[3] Due, J., Feng, Y., \& Zhou, C. (2014). Gamification for Behavior Change of Occupants in Campus Buildings (Unpublished master dissertation). Duke University.

[4] Energy Statistics. (n.d.). Retrieved March 15, 2016, from http://www.tuik.gov.tr/PreTablo.do?alt_id=1029 Türkiye İstatistik Kurumu (TUIK).

[5] Grossberg, F., Wolfson, M., Mazur- Stommen, S., Farley, K., \& Nadel, S. (2015). Gamified Energy Efficiency Programs. American Council for an Energy-Efficient Economy.

[6] How is electricity used in U.S. homes? (n.d.). Retrieved February 11, 2016, from https://www.eia.gov/tools/faqs/faq.cfm?id=96

[7] U.S. Energy Information Administration - EIA - Independent Statistics and Analysis

[8] How We Use Energy. (n.d.). Retrieved April 3, 2016, from http://needtoknow.nas.edu/energy/energy-use/. The National Academies of Sciences

[9] Kankaanranta, M., \& Neittaanmäki, P. (2009). Design and use of serious games. Dordrecht: Springer.

[10] Klemetti, M., Taimisto, O., \& Karppinen, P. (n.d.). The Attitudes of Finnish School Teachers Towards Commercial Educational Games. Design and Use of Serious Games, 97-105.

[11] Knol, E., \& Vries, P. W. (2011). EnerCities - A Serious Game to Stimulate Sustainability and Energy Conservation: Preliminary Results. ELearning Papers, 25th ser. Retrieved from http://ssrn.com/abstract=1866206

[12] Laamarti, F., Eid, M., \& El Saddik, A. (2014). An overview of serious games. International Journal of Computer Games Technology. Hindawi Publishing Corporation.

[13] Lebram, M., Backlund, P., Engström, H., \& Johannesson, M. (2009). Design and Architecture of Sidh - a Cave Based Firefighter Training Game. Design and Use of Serious Games, 19-31.

[14] Marne, B., Wisdom, J., Huynh-Kim-Bang, B., \& Labat, J. (2012). The Six Facets of Serious Game Design: A Methodology Enhanced by Our Design Pattern Library. 21st Century Learning for 21st Century Skills, 7563, 208-221.

[15] Michael, D., \& Chen, S. (2006). Serious Games: Games That Educate, Train and Inform. Boston, MA: Thomson Course Technology.

[16] Michaud, L., Alvarez, J., Alvarez, V., \& Djaouti, D. (2010). Serious Games: Training and teaching, Healthcare, Security and defence, Information and communication (2nd ed.). Montpellier: IDATE.

[17] National Energy and Education Development. (2016). Saving Energy at Home and School [Brochure]. Manassas, VA: Author. Student and Family Guide

[18] Schuller, B, W, Dunwell, I. Weninger, F, \& Paletta, L. (2013). Serious Gaming for Behavior Change: The State of Play. IEEE Pervasive Comput. IEEE Pervasive Computing, 12(3), 48-55. doi: $10.1109 / \mathrm{mprv} .2013 .54$

[19] OECD. Household Behaviour and the Environment: Reviewing the Evidence. (2008). Paris.

[20] Jonathan Kaplan. (2010). Eat Green: Our everyday food choices affect global warming and environment [Brochure]. Author.

[21] Water Program. (n.d.). Retrieved April 10, 2016, from http://www.gracelinks.org/824/water-program

[22] Wood, G., Horst, D. V., Day, R., Bakaoukas, A. G., Petridis, P., Liu, S., Pisithpunth, C. (2014). Serious games for energy social science research. Technology Analysis \& Strategic Management, 26(10), 1212-1227. doi:10.1080/09537325.2014.978277 